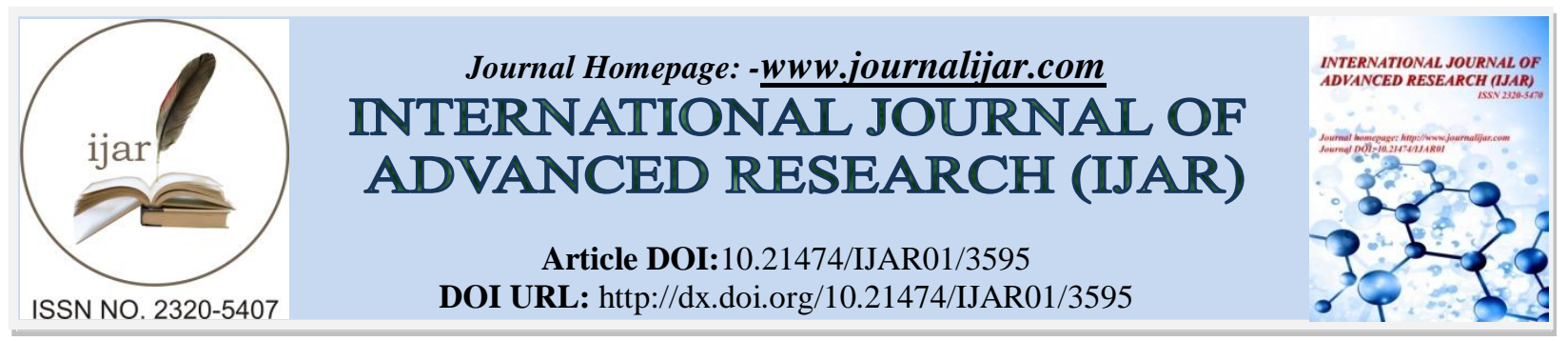

RESEARCH ARTICLE

\title{
MULTI-CHANNEL MEDIA ANNOTATION USING SOCIAL ACCESSIBILITY COMPUTING.
}

\author{
Gayathri. $S^{1}$, Dinesh. $K^{1}$ and Saranya. $S^{2}$ \\ 1. Department of Computer Science, School of Engineering and Technology, Pondicherry University,Puducherry, \\ India. \\ 2. Department of Management Studies, School of Management (DMS), Pondicherry University, Puducherry, \\ India.
}

\section{Manuscript Info}

Manuscript History

Received: 05 January 2017

Final Accepted: 07 February 2017

Published: March 2017

Key words:-

Low vision people, SOMDVIC [social multimedia descriptive system for visually challenged] app, media capture and admin activities.

\begin{abstract}
towards technology. Low vision persons make use of vision and other senses to understand and learn. Low vision means severe visual impairment; they cannot read the content at a normal viewing distance, even with the help of power glasses or with lenses, not with necessarily limited to distance vision. Carrying out of their daily activities is often a major problem. Activities that are previously taken for granted, such as dressing, eating, writing, travelling and simple communications or interacting with other people are hampered. One of the mobile applications was proposed to facilitate them, to identify and tell the things or information through voice by a social networking people using photos, videos or by sending portable document format [pdf] image which is to be uploaded by the low vision people. This will help them to identify things which are before them without interacting with their neighboring people so that they can proceed in a hopeful manner. This paper was proposed with a mobile application developed for low vision people.
\end{abstract}

Today, we are in modern world;

Copy Right, IJAR, 2017,. All rights reserved. it is changing at neck speed

\section{Introduction:-}

Internet and mobile computing bring much convenience to most people. Some may have a wrong opinion that persons with disabilities, those visually impaired or low vision, are unable to use mobile devices and mobile applications. Mobile application developers are not aware of the disability groups in using mobile devices of their special needs. Persons with disabilities are using touch screen mobile devices nowadays. Mobile devices and applications, Information and Communications Technology are used by visual impairment people anytime and anywhere more effectively, live more independently and participate fully in the society.

\section{Accessibility of Mobile Applications:-}

A high responsibility was given for mobile communications for doing businesses and for delivering a wide range of applications. So making accessible applications in mobile not only benefits the people with disabilities but also fulfills legal understanding and responsibilities, building corporate image and widening customer base. For enterprises and organizations opportunities opens to develop accessible applications on mobile platform in order to develop the fast growing digital economy and harness the technology innovation. It is necessary for mobile

Corresponding Author:- Gayathri. S.

Address:-Department of Computer Science, School of Engineering and Technology, Pondicherry 
application developers that there is need and importance of accessibility requirements of mobile applications with the different needs of different segments of the community. There are two types of accessibility in mobile apps

- Automated. E.g.: using algorithms.

- Social network. E.g.: involves humans.

A. Mobile Applications

Mobile applications are of 3 different types which are as follows

- A web app is launched by mobile browser and it was an internet based application.

- A native app can be downloaded it is a platform specific software and it can be used even though in offline.

- A hybrid app is a combination of both native app and web app.

Mobile applications are usually referred to native apps or hybrid apps which require downloading and installation on a mobile device

\section{Literature Survey:-}

Low vision is ubiquitous problem for people having difficulty in viewing objects even with correct lenses. Persons with low vision use mainstream computing devices, to access information when accessibility tools provide sufficient support remains understudy [37] findings delivers the needs of low vision people and improved design opportunities for low vision accessibility tools. It is a major problem in our day to day society. Even then technology is always one step before and new inventions are found before we address the accessibility problems for low vision people. Addressing these issues is very difficult for making new inventions are mobile devices and tablets where there is no proper set of guidelines [21]. Independence and mobility are other important problems with people having visual impairment, they often face difficulties in their navigation [8] accessibility collaborative makes improvement to make web more adaptive to improve process with invited users [10]. Social Accessibility project is a new driven improvement for collaborative metadata authoring technologies [38] interface and applications are written by developers [1]. Several middleware models are proposed and graph sketching tool, blind screen reader, node-link diagrams are shared with sighted people [3] with a real time. 3D's and accessibility dimensions of the built environment [5] specifically, they highlighted that human computer interfaces at the time generally failed to take into account the needs of disabled users. Appliance reader broadly describes the hybrid approaches, which combines human and machine intelligence for interactive access technology [7]. An exploratory study describes the development of access lens hardware and software, the interactive design of access lens in collaboration with blind computer users[12] the characteristics of CS in context makes possible pathways in the field[13]. In addition to compatibility having screen readers, refreshable braille displays and magnification software is designed to low vision users [17]. The mobile cloud computing is becoming a dominant way for various mobile applications [19]. SIMON use ICT services to promote mobility impaired people in the context of on-street public parking areas and multiple transport modes [22] access to information by disabled people has been hampered by short sightedness on the part of computer and communication systems designers [23]. Information and communication technologies (ICTs) become diffuse, with developers and designers to consider users with disabilities and aging populations [27]. Front-end users with mobile devices and back-end cloud servers includes mobile cloud computing. This module helps to access a big volume of storage with distributed portable devices [29] research reveals creativity to CS as a pathway [30]. As ASSETS attendees, it is clearly promoting accessibility computing. Most such courses are aimed at upper-level students [31] Helping users with visual impairments understand the actual issues is a crucial and challenging topic, and will lead to improved accessibility[32] a combined Cloud-Internet of Things (IOT) paradigm provides scalable on-demand data storage and resilient computation power at the cloud side as well as anytime, anywhere[33] The need to study representative users is widely accepted within the human-computer interaction (HCI) community[34] present a case study with the evaluation of four e-government mobile applications.

\section{EXISTING SYSTEM:-}

\section{Visual impairment:-}

Persons with visual impairment who are having low vision, color blindness or color deficiency, are unable to see the screens and controls in mobile applications. Due to their visual constraints, they cannot see the buttons and use a touch screen to access and navigate the mobile application functions. Most persons with visual impairment rely on a screen reader to operate computers as well as mobile devices. A screen reader is software for converting information displayed on the device screen into speech or Braille on a Braille display. Some mobile device has gesture features with screen readers so that persons with visual impairment can hear functions and operate the functions through touch. 
Accessibility features:-

- $\quad$ Screen reader - Nowadays, mobile devices have built in screen reader to facilitate the needs of people.

- Adjustable font sizes - it is used to enlarge the font size in mobile applications through built in feature.

- Screen magnifier - to enlarge the display screen.

- Adjustable brightness/contrast controls - This is used to increase the background color of the screen according to the individual needs.

- Backlit display - it is used to change the contrast of the screen in outdoors.

- Voice recognition -it is used to control the mobile devices through voice commands.

Accessibility Inspection Tools:-

Some of accessibility issues can be detected using inspection tools and/or simulators. It is recommended to test the mobile application with these tools during development stages as early as possible.

- Color Contrast Check

- WCAG Contrast checker (Firefox plugin)

- Mobile Speak for Windows Mobile (Third-party)

- Talkback for Android (Third-party)

- Voiceover for IOS (Built-in)

\section{PROPOSED METHOD:-}

This application is developed especially for low vision people to enhance information through voice by social network people through photos, videos or by sending portable document format [pdf] image by them. When this application is created for mobile phones, it is very useful for low vision people to identify the object which can't be identified by them. Developing android application for this challenging environment results in enhancement of low vision people for their virtual vision. This App is named as "SOMDVIC" which works for the low vision people. It works with text message along with voice.

How the app Works:-

- Open the app and touch the screen to recognize your voice for photo or video routine

- Touch to take photo

- Once again touch to send sms.

- Admin will receive a message with a link

- Through that link photo gets uploaded for view

- Admin replies a text

- User receives a voice message about that photo.

- Video gets opened at last to save the thing in that mobile phone.

\section{Features}

- Voice message

- Speech Recognition

- Photo capture

- Video capture

- Sending and receiving message through server.

\section{Advantages over an existing system:-}

- This app will facilitates the need of low vision people by sending the image of a thing.

- This app provides voice message for low vision people to be clear in their proceedings.

- This app created in Android mobile, will help low vision people anywhere in the surroundings to know their needs.

\section{EXPERIMENT AND RESUlt ANALYSIS:-}

Implementation Tool:-

It is an android based mobile application so one should have android mobile phone to use this application. 
Least Hardware Requirement Environment

TABLE 1:-

\begin{tabular}{|l|l|}
\hline Hardware & Least requirements \\
\hline System & Windows $7[64$ or 32 bit $]$ \\
\hline Hard Disk & $500 \mathrm{~GB}$ \\
\hline Monitor & 15 inch color \\
\hline RAM & $2 \mathrm{~GB}$ \\
\hline
\end{tabular}

Software Requirements:-

This Application is supported by android mobiles having lower version of API 8: ANDROID 2.2 [Froyo] to API 18: ANDROID 4.3 [JELLY BEAN].

\section{Software used:-}

adt-bundle-windows-x 86-20130917

The bundle comprises of eclipse android development tool with SDK manager build: v22.2.1-833290

Development tool:-

Eclipse android development tool with an android Emulator.

SOMDVIC Mobile application development:-

The SOMDVIC application is developed using eclipse android development kit. Code was made using java programming language. The user interface is created using XML language.

\section{Server:-}

Mobile application server consists of operating system and server hardware. These functions on side by side allow the server to remote access and provide services to apps, which contains security features, authentication and updates. In this, the mobile app server communicates with the client to enhance data and balancing load. It makes the admin to configure settings, make out updates and wipe the data's from current location.Because this app is a type of hybrid mobile application we can use any type of server side technology, like a classic web server technology (using JAVA, PHP or .NET) or some kind of cloud technology. Eg: Parse.com

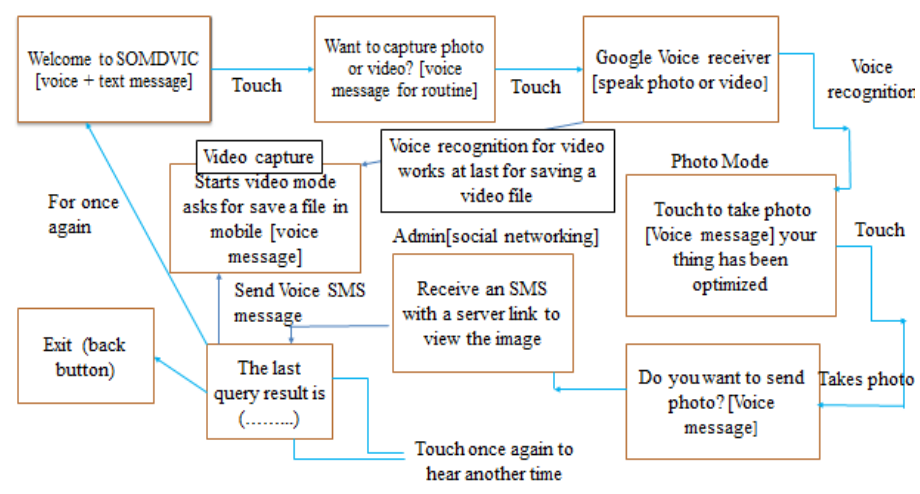

Server used for this App:-

Fig. 1:-Overall Module

In this App, server is used as a kind of cloud technology for loading and storing of data. The Cloud Technology used in this App is Heptotechnologies.com

A. Modules

The modules involved in the design of this application are as follows

1. Media Capture

- Image Capture.

- Video Capture.

2. Admin

- SMS activity [Sending and receiving SMS]

- Server Link 


\section{Media Capture:- \\ Image Capture:}

This app is developed for low vision people to capture images hence photo mode is used in such a manner to take photo. In this photo module, the resolutions are set out in pixels to capture images in good looking manner. If the persons changes in different directions also it takes the image in pixel format. Touch makes to take photo.

\section{Video Capture:}

Video Capture is done in this app for saving things which are captured as an image. People having low vision are not able to see some views clearly so this app facilitates image but it is not saved in their app hence for future reference this app provides an option of video capture to capture videos. Video mode is carried out by voice recognition at the beginning of the application, at last it takes to this mode to save videos. Touch to start, end and save videos. If you don't want a video option, leave it as such don't speak when voice is recognized.

\section{Admin Module:-}

\section{Sms activity:-}

After image capture is over, the image has to be send to the Admin mobile. The Admin is the social networking person who helps the low vision people to understand the image send by them through voice. After taking image, the person has to touch the screen to send sms to admin. Admin will receive the sms as an server link. Hence after viewing the image the admin will send the reply as an message. It will be received in this app through voice. Steps involved are

- Sends sms after the image was taken.

- Admin receives sms.

- Admin opens the image through server.

- Admin reply through sms.

- Low vision identify by voice message through this app.

\section{Server link:-}

As soon as the message is received by the admin, he/she views the message as a text with link when the admin touches the link it opens the cloud server link and displays the image. Cloud server is the one which stores data in its server. After viewing the image the admin came to know about the image. The admin will reply through sms to that application.

\section{Procedure to use the app:-}

This is the first viewing screen for SOMDVIC app, next touch the screen Figure 2.

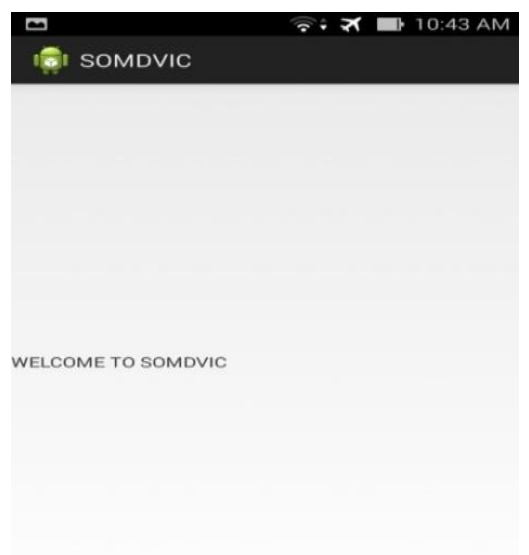

Fig. 2:- Application

It will show Google voice recognition to speak Figure 3. Next this Google voice recognition is used for finding photo or video mode. 


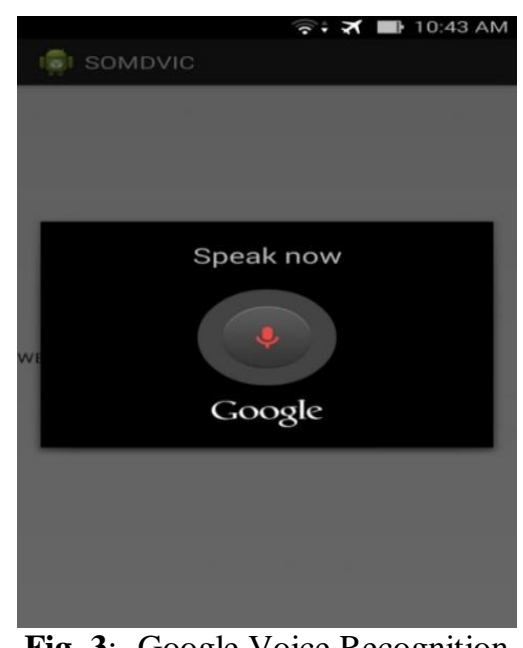

Fig. 3:- Google Voice Recognition

Sometimes it may fail also because of insufficient network facilities but it used for mode change in this application it is shown in Figure 4.

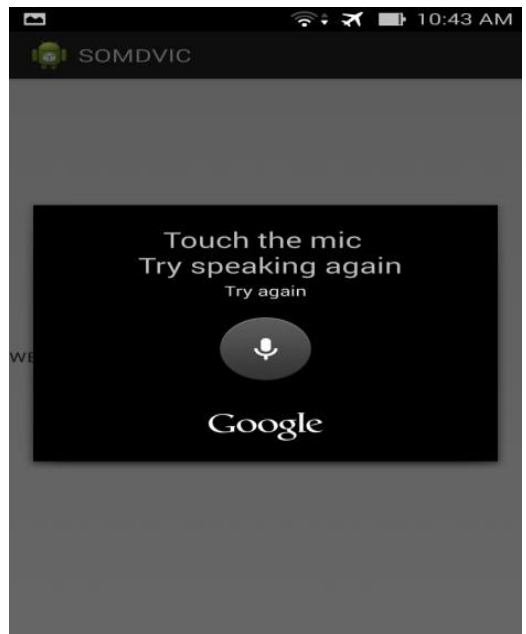

Fig. 4:- Google Voice fails to capture your voice

If you speak photo it takes you to the photo mode as shown in the figure 5.

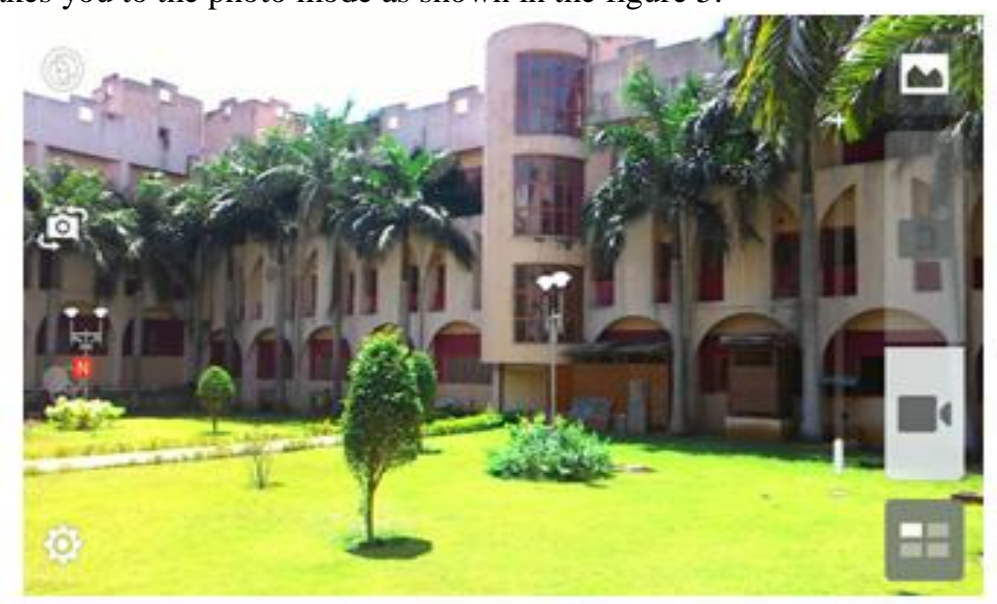

Fig. 5:- Photo mode 
If you speak video, it takes you to the video mode as shown in the figure 6 .

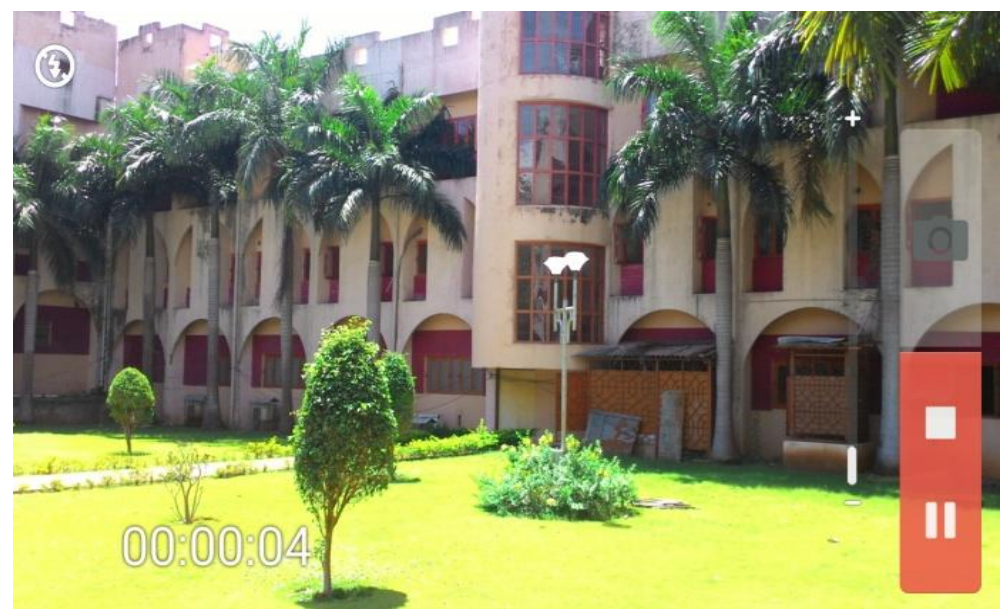

Fig. 6:- Video mod.

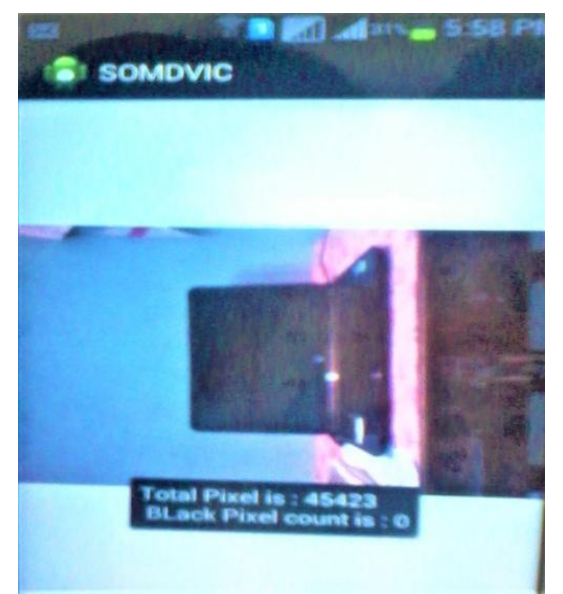

Fig. 6:- Laptop photo capture in this App

Now the app takes this laptop in the photo mode and again touches to send the SMS to server. The laptop is taken as a picture in photo mode and it was shown in the figure 6.

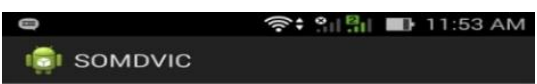

THE LAST QUERY RESULT IS This is laptop

Fig. 7:- Server reply through App 
Social networking people receive this message to give back the reply. If they type it is a lap it will be received by this SOMDVIC app and it is replied through voice in that app as shown in Figure 7.

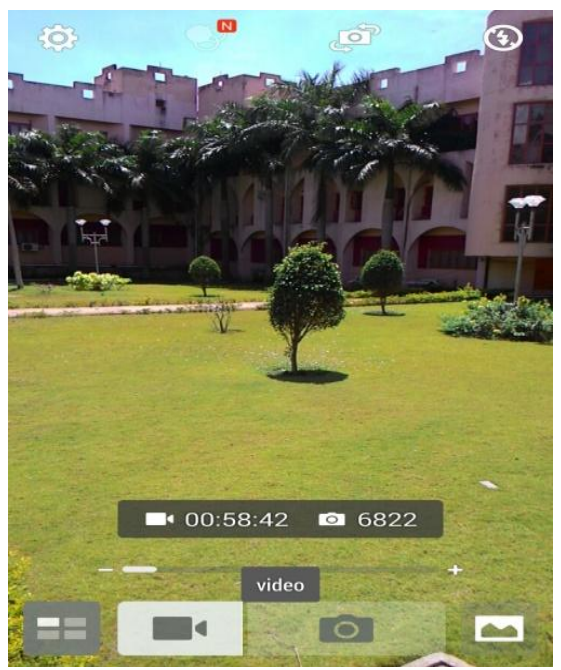

Fig. 8:- Saved video can be watched.

Video can be also be captured using this application and it was saved using options in this application and it can be viewed later or send it to server to get the information used in that video. The image used for video capture shown in Figure 8. We can watch the saved video.

\section{Conclusion:-}

It is difficult to adopt a technology for people with physical disabilities compared with normal people. The mobile app had been developed for low vision people across the world. Android applications are not very much common for low vision people, but they are using and accessing it in their daily activities to some extent. Many smartphones app has usability issues for low vision people. In this app, we evaluate the image of anything, through which low vision people came to know about the image for further enhancement process. This will help them to identify things which are before them without interacting with their neighboring people. This app was created as a guidance to increase the smartphone application for low vision people. The result of using this app, is better in terms of usability, persons have low vision find their routine daily works easily to accomplish it.

\section{Future Work:-}

This application was proposed, it provides a way for better application development to help low vision users to carry out their routine tasks efficiently and smoothly with the help of latest technologies. In Future, this app can be connected to what Sapp, twitter etc., to enlarge social networking environment for low vision people.

\section{Acknowledgment:-}

GAYATHRI.S received the degree in master of computer science from Pondicherry University in 2015. Currently, she is an M.Tech student at Pondicherry University. Her interests are in Advanced Mobile Technologies and AI.

\section{References:-}

1. J. H Andrews, "Johar: A Framework for Developing Accessible Applications," 243-244, 2009.

2. S.T. Azad, "A Model for using and Coordinating Heterogeneous Mobile Service Providers," 12-18.

3. S. Balik, S. Mealin, M. Stallmann, R. Rodman, M. Glatz\& V. Sigler, "Including Blind People in Computing Through Access to Graphs," 91-98, 2014.

4. G. Chen, \& F. Rahman, "Analyzing Privacy Designs of Mobile Social Networking Applications", 2008.

5. J. Comendador, M. E López-lambas, \& A. Monzón, "Urban built environment analysis : Evidence from a mobility survey in Madrid," Procedia - Social and Behavioral Sciences, 160 (Cit), 362-371, 2014.

6. E. P Glinert, \& B. W York, "Computers and People with Disabilities," 1(2), 1-7, 2008.

7. A. Guo, "Appliance Reader: A Wearable, Crowdsourced, Vision-based System to Make Appliances Accessible," 2043-2048, 2015. 
8. V. L. Hanson, "Computing for Humans," 54(12), 2014.

9. D. Hoffman \& L. Battle, "Emerging Issues, Solutions \& Challenges from the Top 20 Issues Affecting Web Application Accessibility," 208-209, 2005.

10. C. Holotescu, \& G. Grosseck, "Mobile learning through microblogging," Procedia - Social and Behavioral Sciences, 15, 4-8, 2011.

11. A. Ismail, \& K. S. Kuppusamy, "Accessibility of Indian universities. homepages : An exploratory study," Journal of King Saud University - Computer and Information Sciences, 2016.

12. S. K. Kane, B. Frey, \& J. O. Wobbrock, "Access Lens: A Gesture-Based Screen Reader for Real-World Documents," 347-350, 2013.

13. M. Knobelsdorf, "Computer Science in Context - Pathways to Computer Science," 88, 65-76, 2008.

14. M. Knobelsdorf, \& R. Romeike, "Creativity as a Pathway to Computer Science," 286-290, 2008.

15. R. E. Ladner, “Accessibility Is Becoming Mainstream, (September 2014),” 98195.

16. R. E. Ladner, "M p b a r, (110)," 5-16, 2014.

17. S. Ludi, \& L. Ellis, “An Accessible Robotics Programming Environment for Visually Impaired Users," 237238, 2014.

18. A. R. Maria, "Mobile Application for Tracking Data from Humidity and Temperature Wearable Sensors," 1-4, 2015.

19. P. Mehrotra, "An Efficient Model for Privacy and Security in Mobile Cloud Computing," 2014.

20. M. Montagnuolo, A. Messina, V. Cavalli, , E. K. Kolodner, D. Chen, K. Meth, \& P. Ta shma, "Supporting Media Workflows on an Advanced Cloud Object Store Platform," 384-389, 2016.

21. L. Moreno, "Accessibility to Mobile Interfaces for Older People. Procedia - Computer Science, 27(Dsai 2013)," 57-66, 2014.

22. E. Muñoz, M. Serrano, M. Vivó, A. Marqués\& A. Ferreras, SIMON : asSIsted Mobility for Older aNd impaired users," 14, 4420-4429, 2016.

23. A. F. Newell, “Accessible Computing - Past Trends and Future Suggestions,” 1(2), 1-7, 2008.

24. D. Nyambo\& C. Tarimo, "Security Frameworks in the Converged Web and Mobile Applications : A Review," 29-34, 2014.

25. G. M. Poor, L. M. Leventhal, \& J. Barnes, "No User Left Behind: Including Accessibility in Student Projects and the Impact on CS Students Attitudes," 12(2), 1-22, 2012.

26. G. M. Poor, L. Marie, L. Scott, K. Jordan \& R. Samuel, “Thought Cubes : Exploring the Use of an Inexpensive Brain-Computer Interface on a Mental Rotation Task," 291-292.

27. C. Putnam, \& M. Dahman, "Best Practices for Teaching Accessibility in University Classrooms : Cultivating Awareness, Understanding, and Appreciation, 8(4)," 1-26, 2016.

28. C. Putnam, M. Dahman, E. Rose, J. Cheng \& G. Bradford, "Teaching Accessibility, Learning Empathy, (c)," 333-334, 2015.

29. W. Ren, L.Yu, R. Gao, \& F. Xiong, "Lightweight and Compromise Resilient Storage Outsourcing with Distributed Secure Accessibility in Mobile Cloud Computing," 16(5), 520-528, 2011.

30. R. Romeike, "Towards Students Motivation and Interest - Teaching Tips for Applying Creativity," 113-114, 2008.

31. B. J. Rosmaita, “Accessibility Now! Teaching Accessible Computing at the Introductory Level,” 277-278, 2006.

32. Sato, D., Takagi, H., \& Kobayashi, M. (2010), "Exploratory Analysis of Collaborative Web Accessibility Improvement," 3(2).

33. C. Science, "A Robust and Flexible Access Control Scheme for Cloud-IoT Paradigm with Application to Remote Mobile Medical Monitoring," 2015.

34. A. Sears, \& V. L. Hanson, "Representing Users in Accessibility Research,” 4(2), 1-6, 2012.

35. L. C. Serra, L. P. Carvalho, L. P. Ferreira, J. Belimar, S. Vaz\& A. P. Freire, "Accessibility Evaluation of EGovernment Mobile Applications in Brazil. Procedia - Computer Science, 67(Dsai)," 348-357, 2015.

36. A. Sey\& M. Fellows, "Loose Strands : Searching for Evidence of Public Access ICT Impact on Development," 189-194, 2011.

37. S. Szpiro, "How People with Low Vision Access Computing Devices: Understanding Challenges and Opportunities," 171-180.

38. H. Takagi, “Collaborative Web Accessibility Improvement : Challenges and Possibilities,” $195-202$.

39. S. Vickers, H. Istance\& A. Hyrskykari, "Performing Locomotion Tasks in Immersive Computer Games with an Adapted Eye-Tracking Interface," 5(1), 2013. 